\title{
针对印尼国别汉语教材编写原则的研究 \\ STUDY OF PRINCIPLES FOR COMPILING COUNTRY-SPECIFIC CHINESE TEACHING MATERIALS FOR INDONESIA
}

\author{
Kelly Rosalin \\ Chinese Department, Faculty of Humanities, BINUS University \\ Jln. Kemanggisan Ilir III No.45, Kemanggisan - Palmerah, Jakarta Barat 11480 \\ krosalin@binus.edu
}

\section{内容摘要}

本文通过对印尼语版的《当代中文》教材的分析, 发现针对印尼学生这本教材在课文内容、翻译以 及语境部分还存在一定的问题。因此, 在为印尼学生编写教材, 需要考虑到教材编写的语言原则、文化 原则、以及教学原则三个方面中的 “五性”。

关键词: 《当代中文》; 国别教材；编写原则；印尼

\begin{abstract}
This article analyzes an Indonesian version of Contemporary Chinese teaching material. It is found that in this teaching material there are several problems relating to the content of text, translation, and context of text if it is used by Indonesian students. Therefore, it needs to consider "five elements" of language, cultural, and teaching principles in compiling the Chinese teaching materials for Indonesian students.
\end{abstract}

Keywords: Contemporary Chinese, Country-Specific Teaching Materials, Compiling the principles, Indonesia 


\section{引言}

编好国别汉语教材往往离不开通用性教材的编写原则。国别教材与通用性教材的不同就是 国别教材需要尊重国别特色。因此，我们应该先了解教材编写的基本原则。

刘询把汉语教材的编写原则概括为 “五性”: (1) 针对性, 教材要适合使用对象的母语、 文化背景、国别、年龄、文化学习目的、学习的起点与学习的时限; (2) 实用性, 教材内容要 从学习者的需要出发, 语言材料要有真实性、来源于生活、现实, 要利于贯彻精讲多练与要使 教学过程交际化; (3) 科学性, 要教规范、通用的语言, 教材内容要符合语言教学的规律, 解 释要注意准确性等; (4) 趣味性, 教材内容和形式生动有趣, 内容是学生所需要的, 题材多样 化, 教材内容反映现实问题并要逐步加大文化内涵; (5) 系统性, 内容介绍与技能练习方面要 平衡协调等。“五性” 是编写对外汉语教材要遵循的原则。

虽然印尼语版的《当代中文》是一套专门针对母语为印尼语的汉语零起点学习者而设计 的, 但是真正地去针对印尼学生, 这本汉语材中的课文内容部分、翻译部分还存在不少的问 题。尤其是翻译部分, 它比其他部分出现问题比较多。虽然翻译部分存在的问题比较多, 但是 面对印尼学生的汉语国别教材, 内容部分与情景部分对印尼汉语国别教材的影响力是最大的。

鉴于印尼语版的《当代中文》教材中的种种问题考察, 本文认为, 编写印尼国别汉语教 材, 应该真正地以印尼学生为中心。对此以下本文认为适合印尼学生的汉语国别教材的编写要 求主要有三个原则, 语言原则、文化原则与教学原则。

\section{内容}

\section{语言原则}

通过所提出的问题考察，本文中对语言原则有个概括，所谓的 “语言原则” 是指在教材编 写内容方面、词汇方面以及对词汇翻译解释方面需要更加注意以及具有针对性和科学性的原 则。语言原则方面主要所涉及到教材中的语用语义、翻译解释、词汇等方面, 而语言原则的 各个方面都存在在这些教材中的内容、翻译与情景部分。如:

在课文内容中出现的是 “坐 139 路公共汽车”, 内容部分存在印尼与中国对公交线路不同 的用语的问题等等。在翻译部分, 这些汉语教材中的印尼语译释问题出现的比较多, 如: 把 “他” 译释为 “baliau”、“干杯” 译释为 “toast”、“别着急” 竟然翻译成 “kalem” 等等, 这些 印尼语译释都不够准确, 而在情景部分, 有些课文内容也出现人物名字是以来中国学习汉语的 其他国家留学生状况而选用的名字，如：金容南、田中等。这些都与印尼的实际生活环境相差 甚远, 因此学生接受起来会存在一定的难度, 尤其是日常会话, 更容易使学生缺乏带入感。

在编写中会造成这样的问题是因为编者不了解印尼情况, 并且没有将教材内容与印尼当地 学习者所处的非语言环境相结合。因此, 为印尼学生编写汉语国别教材时, 编写者在语言原则 上必须注意到针对性和科学性的基本原则。 


\section{针对性}

针对性是对外汉语教材编写的一个基本原则。因此, 教材要适应使用对象的特点。在语言 原则上, 编者在编写印尼汉语国别教材应该考虑到教材中的内容部分与情景部分需要遵循针对 性。在语言原则的针对性可以考虑以下的建议:

\section{教材要适合印尼学生的学习环境}

印尼学生学习汉语处于在非语言环境的情况下。除了在课堂以外, 学生很难接触到好的学 习汉语环境。为了让学生更了解课文中的内容, 课文中选用的地名名词与人物名词应该要贴近 学生的生活。因此, 学生对课文内容比较熟悉并能把汉语和自己的学习环境、生活联系起来。 虽然地名名词应该贴近所在的当地的地名, 但是在学习汉语也离不开中国的一些地名, 学生也 需要了解中国的一些城市, 所以在选用中国地名时, 应该是中国比较有名的地方, 如: 北京、 上海、广州等等, 而避免地方色彩过于强烈的专用名词像 “紫竹园” 的地名。教材所选用的人 物名字也需要体现出印尼国别教材的特征, 教材中的人物名字应该使用印尼名字, 例如: 阿 迪、安迪、穆罕默德、琳达、索妃雅等等。

\section{词语用语要考虑到实际情况}

词汇具有传递信息的作用, 没有词汇就无从交际。因此, 在为印尼编写汉语教材时, 要顾 及印尼社会的生活所需要的词汇, 从而可以让学生能很好的掌握之后, 学生能把所学的词汇适 应印尼社会的生活, 使他们在使用汉语沟通的时候, 能把汉语词语用语恰当地引用到当地实际 情况及生活。因此, 学生能准确地表达自己的想法。

此外, 编者在为印尼学生编写教材的时候, 也要考虑到在教材常出现的比较 “中国化” 的 词语, 并且与印尼的教学环境相结合。为了是学生更容易接受具有针对性的有印尼语言环境特 色的汉语教材, 应当在教材中更多地使用符合印尼情况的词语, 更具有印尼针对性的词语来代 替。

\section{科学性}

教材的科学性强调几点, 其中一个是对语言现象的解释要注意准确性。在教材编写的语言 原则上, 科学性主要是指翻译部分。编写教材中翻译部分应该要更加注重, 因为印尼语注释对 零起点的印尼学生是一种非常重要的工具, 具有帮助学生学习的作用。但是在印尼语版的《当 代中文》这套教材中的翻译部分存在着一些列的问题。比如: 将 “眼镜” 翻译成 “kata mata”、

“熟悉” 被翻译成 “tabu dan kenal benar akan”。这些例子有很明显的错误并学生读了该词的印 尼语译释后容易误导学生。

可以说, 对于初学者来说, 印尼语一一既初学者母语的翻译会对初学者起到非常重要的指 导作用。通过这些印尼语的注释, 学生能够根据自己的母语更准确地理解学习内容。因此, 加 强汉语教材相关印尼语的翻译注释的准确性和科学性, 从而避免由于翻译注释的错误造成对学 生的误导。

\section{文化原则}

学好文化才能学好语言, 相反不学好文化就不可能学好语言, 语言与文化有密切的关系。 因此, 在编写汉语国别教材应该注意到文化原则。文化原则是其中一个教材编写的通用原则。 
文化原则是指在教材编写课文内容方面要注意具有针对性和实用性的原则, 并考虑到目的语文 化与学习者母语的文化之间的关系。

从教材内容方面来看, 教材的课文中出现了一些关于喝酒、彩票等话题, 以及在情景部分 出现的天气季节等问题, 这些内容都不符合印尼学生的实际生活环境情况。这主要是由于文化 差异而造成的，在编写过程中编者没有仔细考虑到中国与印尼之间不同文化环境、风俗背景的 区别, 只是简单地将教材人物地身份背景与会话的环境背景改为印尼, 但是具体课文内容却没 有进行深入严谨的修改，因此使教材内容与印尼的实际情况之间存在着比较多的矛盾。

如果教材中存在的文化差异比较严重的话, 可以引起矛盾和冲突。要了解中印尼之间的文 化差异并了解什么样的中国文化内涵才能融入到印尼教材是编者在编写印尼汉语国别教材中非 常重要的基础, 这样才能避免教材中可能会出现的一些交际障碍的因素。因此, 编写者在文化 原则上必须注意到针对性和实用性的基本原则。

\section{针对性}

针对性是作为汉语国别化教材最重要的一个原则。国别化和通用性教材有区别就是比通用 性教材更强调针对性。为适应印尼多元语言文化社会的情况, 文化原则的针对性可以考虑以下 的建议:

\section{要注意到宗教的禁}

印尼是一个多民族、多文化的国家，共有 134 个群族 (Suku Bangsa), 也是多宗教的国 家，是世界上穆斯林人口最多的国家，而且信奉伊斯兰教的居民占 $88 \%$ 。由于信仰伊斯兰教 的印尼人比较多, 所以伊斯兰教对印尼的政治与印尼人日常生活的方方面面都有着比较突出的 影响，伊斯兰文化已经深深地融入到印尼社会生活中的各个领域。因此，在编写教材中应该考 虑到宗教所禁忌的项目, 并尽量避免这些项目, 以免因此文化差异而产生矛盾或理解方面的障 碍。

\section{课文内容要与印尼国情、民俗互相结合}

教材编写内容需要考虑到内容是否反映印尼的国情特点。即便是讨论印尼的社会和文化, 教材内容也不能仅仅说到印尼伊斯兰教, 而且也要考虑到印尼的多元文化, 如也要将在印尼汉 语学习者中所占比例较大的印尼华裔汉语学习者的文化背景揉入课文内容中, 课文内容并可以 涉及到中国与印尼在日常生活中有所不同的地方。这样才能使学生增强语境的带入感, 激发学 生的学习兴趣, 同时对于加深学生对于相关汉语内容的印象也更加有效。因此, 学生通过课文 内容能更了解中国的情况, 使学生可以更为贴近中国的语言环境。

\section{所设计的情景要与生活、交际相结合}

在教材编写中, 要注意到课文中所设计的情景是否适合印尼的生活习惯。如果情景所设计 的不符合印尼的生活情况, 会导致学生很难理解课文中的内容, 因此对学生的学习也会产生一 定的障碍。

课文中所设计的情景也要符合逻辑, 并且情景与人物的情况也要一致, 如在印尼语版的 《当代中文》教材中出现了许多人物情况与课文中的情景不一致、前后内容或人物关系相互矛 盾的问题。因此, 在编写教材课文时, 应当有针对性的注意教材内容与印尼环境的统一与相互 之间的适应，这样才能有利于学生充分了解与掌握教材中涉及的内容。 


\section{实用性}

在选用教材语言材料的过程中要考虑到该语言材料是否具有实用的意义。如果没有实用的 意义, 这样的内容就没有必要出现在教材中。在印尼学习汉语是属于非汉语语言环境, 因此在 编写教材时就要把课文内容设计得更为符合印尼的语言交际情景, 帮助学生在现实生活的情景 中可以实际运用自己所学到的汉语知识, 用汉语讨论在生活中经常会遇到的各种情景。

总之, 要使得教材发挥更大的作用, 具有更强的实用性与针对性, 就要把教材中的课文内 容设计得更加贴近学生的实际学习生活, 使汉语在非语言环境的印尼也能更好的融入到学生的 学习生活中去。

\section{教学原则}

教学原则是根据教育教学目的、反映教学规律而制定的指导教学工作的基本要求。它既指 教师的教, 也指学生的学, 应贯彻于教学过程的各个方面和始终。它反映了人们对教学活动本 质性特点和内在规律性的认识, 是指导教学工作有效进行的指导性原理和行为准则。而教材作 为教学过程中至关重要的一环, 因此在编写教材时也必须遵循教学性原则这一标准。

针对汉语教材的编写, 特别是具有针对性的国别教材的编写, 可以将教材编写的教学原则 概括为: 教学原则是指在编写教材的内容时要注意具有针对性、科学性、系统性、趣味性与实 用性的特点, 并有效地进行教学这一必须遵循的最基本原则。在汉语国别教材的编写过程中少 不了教学原则, 因为编写者在做编写工作之前应该先了解当地国家的汉语学习的基本情况, 教 材也要体现教什么、如何教、如何学这几点具有指导作用的特征。因此, 编写适合印尼学生学 习的汉语教材, 应重点考虑如下的基本 “五性”:

\section{针对性}

教材要适合印尼学生的年龄、母语、背景文化、学习起点等等。根据学习者的课堂环境, 可以把印尼汉语学习者分为三类: 第一是在高等院校攻读中文系专业的学生, 第二是在高等院 校把汉语作为选修课的学生, 第三是在汉语培训班学习的学生。各个类型学习者都有所不同的 学习目的, 而成年人的学习目的更明确, 诸如对第一类型的学习者来说, 他们比其他类型的学 习者更喜爱汉语, 以汉语为专业, 也把汉语作为他们就业方向, 可能有的希望将来选择汉语教 师、翻译等行业。第二类的学习者, 因学校要求必须选一个外语作为第二外语, 对汉语有兴趣 的学习者就会选汉语作为选修课。而第三类的学习者, 作为成年人, 其中只有一部分是因父母 的要求才学汉语的, 其余大多数是自愿要学习汉语, 他们学习汉语的原因是准备来中国留学、 工作的需要, 或者出于对汉语或中国的兴趣等等。

另一方面, 由于印尼学生的母语为印尼语, 而印尼语兵部属于类似韩国、日本等汉字圈里 的国家, 印尼语所使用的是拉丁字母, 因此在为印尼编写教材的过程中也要注意到要更多安排 有益于印尼学生练习汉字的项目, 以便减少学生对汉字的陌生感并提高学生的识字能力。同 时, 印尼是一个多元民族的国家, 虽然学生母语是印尼语, 但是从学生的文化背景来看, 印尼 学生都有不同文化背景。由于学习者的不同文化背景, 可以把学生分为有汉语背景的学生和非 汉语背景的学生, 而不是分为华裔和非华裔, 因为不是每个印尼华裔都能说汉语或者汉语方 言。有汉语背景的学生大部分是印尼华裔, 他们除了在课堂上以外, 在社区或者家里也可以接 触、使用普通话或者汉语方言, 如闽南话、福建话、潮州话、客家话等。与之相反, 非汉语背 景的学生, 除了课堂以外, 他们几乎没有很大的机会接触并使用汉语。而笔者也认为学生能不 能说汉语方言对他们说汉语的口音有很大影响。对于会说汉语方言的学生, 他们说汉语时会带 
着中国南方的口音, 而对于没有接触过汉语或者汉语方言的印尼学生, 说汉语时会带着 “洋腔 洋调”的口音。

因此, 要编出好教材, 首先要明确教学对象的差异性以及其学习汉语的目的, 然后再考虑 学生的文化背景以及其他因素。针对不同文化背景、不同教学对象、学习起点等学生的不同需 求来编写汉语教材, 这样才能更加全面地满足不同类型学生学习汉语的需求, 从而是学生通过 对教材的学习掌握汉语知识, 在今后的学习与生活中可以学以至用。

\section{科学性}

汉语教材的科学性最基本要强调的是教材内容的规范性与编排的合理性。教材的规范性是 指内容所使用的语言是否标准, 是否符合汉语普通话标准, 是否符合中国通用的简化汉字标准 等。在编写汉语教材的过程中, 所选用的内容要有科学依据, 而不是随意编排。如在《当代中 文》有些课文情景的准确性还存在着一定的争议, 同时也再一定程度上不符合逻辑性。在针对 印尼学生编写一套汉语教材的时候, 应该更加注意到所编或者选用的内容已经完全准确。如: 印尼语版的《当代文化》中谈关于天气的时候, 对话中发现有一些对话还不符合逻辑性, 因为 在课文中出现的 “我们的冬天比这儿来的晚, 春天比这儿来得早”, 而说话的人是一个印尼华 裔。或者是一些印尼与的翻译注释中存在的明显错误, 这些都没有遵循科学性的原则。

由于国别教材的教学对象多为汉语的初学者, 因此对于教材内容正确与否的辨别能力较 差。因此, 在编写过程中应当更加准以教材内容的科学性, 必须保证教材内容符合正常的逻 辑, 并在语言应用方面十分准确, 这样才能真正起到 “教” 学生的作用, 真正引导学生进行有 意义的语言学习。否则, 如果在教材编写过程中不注意科学性及其验证, 那么不到会误导学 生，也会使教材失去其作为学习材料的最基本的作用。

\section{趣味性}

教材是否符合趣味性原则能明显从教材内容上看出来。在编写教材中需要注意到内容是否 有趣, 有趣的内容才能够吸引学习者的学习兴趣, 这一点对于一门语言的初学者尤为重要。

教材的趣味性就是要把教材内容与学生在现实生活所关注的话题连在一起, 激发学生的学 习兴趣。因此, 在为印尼学生编写汉语教材时, 编写者首先应该先了解什么样的的话题才能吸 引印尼学生的兴趣, 什么样的话题才能激发印尼学生的好奇心。虽然教材的趣味性要求内容必 须有趣, 但是教材内容也必须是学生所需要的。如果在教材的课文内容很有趣, 但是不是学生 所需要的内容, 在现实生活交际中也没办法实际使用所学到的内容, 那么即使学生学习了也会 由于没有实际应用的机会而很快忘记。

教材的趣味性对初、中与高级学生, 都有不同的学习要求。对于初中级学习者, 比较贴近 印尼社会现实生活的话题比较能够吸引他们。因为许多印尼学生认为汉语不好学, 所以教材内 容要从他们最熟悉的话题来引起他们对学习汉语的兴趣, 如印尼人一般在周末干什么、恋爱、 找对象等话题。而且, 教材内容也应考虑到以中国与印尼之间存在的差异性话题作为启发, 如 中国人有睡午觉的习惯, 而印尼人没有睡午觉的习惯, 学生一发现印尼和中国有所不同的地 方, 就能引起学生更强的好奇心, 这也能增加教材的趣味性。另外, 鉴于印尼是个多元文化的 国家, 教材内容也能涉及到印尼各个民族不同饮食习惯、生活习惯等话题, 这样可以激发学生 之间的讨论，提供应用汉语的实践机会。 
学生如果对汉语教材内容感到有兴趣, 他们就不会觉得汉语很难, 反而能更加轻松自在地 学汉语。除了教材内容要求要有趣味性之外, 教材板式的设计也要吸引学生的注意力, 教材中 的图片要生动风趣并能让学生通过图片更容易了解课文的内容。

\section{实用性}

汉语语言教学的最终的目的是为了达到培养学生运用汉语进行交际能力的目标。因而, 在 教材编写过程中也要首先了解学生学习汉语的的目的。

因为中国经济的快速发展，许多中国公司来到印尼发展，因此在印尼的中国公司对员工能 够听说读写汉语的要求也越来越高。为了抓住在中国公司的就业机会或者要从事跟汉语有关的 就业 (当汉语老师), 许多印尼人开始学习汉语, 但也有一些印尼学习者因要去中国留学而学 习汉语。编写者在为印尼学生编写汉语教材时要明确地知道学生学习汉语目的, 才能有针对性 地达到教材的实用性目标。

在印尼要实际使用汉语的机会比较少, 除非学习者以后要与中国有关的部门、公司工作, 或在汉语课堂上以及与汉语学习者之间的对话, 才能实际进行汉语沟通。因此, 学生所学的内 容需要在社会生活中得到更多的使用机会。比如说, 对于要从事与汉语有关的就业学生来说, 教材内容可以设计为在中国公司面试的情况, 怎么接待来中国的客人、怎么跟中国人做生意 等。而且编者能通过教材的练习部分, 提供给学生能够帮助学生达到实用性的目标的一套练 习, 从而使学生能通过练习获得运用汉语进行交际的能力。总之, 对于教材的实用性, 教材内 容要选用适合印尼的真实生活语料, 为了助于印尼学生开展使用汉语的交际活动。所学的内容 应更为贴近学生的学习生活、社会生活以及学习汉语后可能会从事的工作等等。

\section{系统性}

教材的系统性首先在教材编写中应遵循《国际汉语教学通用课程的大纲》和印尼教育部制 定的外语教学大纲的规定。而教材的系统性, 同时也要遵循由易到难, 由熟悉到陌生, 由简单 到复杂, 由浅入深的顺序来安排合理的教材内容。另一方面, 在编写教材内容时应该要注意到 初中级不同阶段的学生对中国文化的理解程度。初级学生对中国接触比较少, 对涉及到中国较 多文化内容的教材理解起来比较难, 所以在这一阶段应尽量避免大量中国文化特征事物的出 现; 而对中级的学生来说, 了解中国文化是十分有必要的, 因此在关于中国文化的课文内容应 该增加辅助性的注释说明, 使学生可以更加深入的了解中国文化。

因为教材的系统性涉及到很多方面，因此，除了教材内容之外，词汇、语言点、练习与辅 助配套材料都必须具有系统性。对于词汇的安排, 在编写教材时, 也要注意到适合初中级的词 汇量、词汇的难易的程度, 而且所出现的词汇也要针对课文内容中的。对于初级的词汇应该更 加关注在生活上能够使用词汇并具有趣味的词汇。对于语法的安排, 应该按照教学大纲的要 求, 而不能一味强调趣味。对于练习的安排, 练习形式要多样化, 并且涉及练习的时候也要考 虑到印尼学生学习的特点, 印尼学生不像欧美学生很主动回答老师的问题, 因此编者可以利用 练习部分来给学生口语练习的机会。此外, 练习部分也应该通过印尼学生容易造成的偏误研究 出发, 哪一方面学生容易错误, 就要把那方面的练习量要比其他的更多。而对于辅助配套材料 的安排, 需要考虑到印尼学习者缺少汉语语言学习环境与印尼汉语教师的能力的因素, 教材除 了课本和练习册以外, 还应该提供配套材料, 如: 录音光盘给学生以及教师手册给教师。

总而言之, 具有系统性的教材对教学才能加强带入感, 把汉语带入到学生的日常生活中并 能使学生感觉到教材是为他编写的, 具有亲切感, 适合他们学习汉语的情况。因此, 可以帮助 学生更加容易掌握汉语。 


\section{结语}

本文认为适合印尼学生的汉语国别教材的编写要求主要有三个原则, 语言原则、文化原则 与教学原则。在语言原则上, 教材内容应遵循教材编写的针对性与科学性; 在文化原则上, 教 材内容应遵循教材编写原则的针对性与实用性; 在教学原则上, 教材内容应遵循教材编写的针 对性、科学性、趣味性、实用性以及系统性。

\section{参考文献}

李禄兴、王瑞.(2008). 国别化对外汉语教材的特征和编写原则. 第九届国际汉语教学研讨会论 文选. 北京: 高等教育出版社.

李泉. (2006). 对外汉语教材研究. 北京：商务印书馆.

薛飒飒. (2010). 情境创设在对外汉语初级口语教学中的运用. 科海故事博览・科教创新. (3)

刘汉武. (2011).越南汉语教材的现状及编写建议. 语言教学研究. (9):116-117

刘询. (2007). 对外汉语教育学引论. 北京: 北京语言大学出版社.

苏月帝. (2008).印尼雅加达汉语状况及其对汉语教学的影响: [硕士学位论文]. 北京：北 京 语言大学.

魏红. (2007). 泰国中学汉语教材编写和使用中的几个问题. 云南师范大学学报. 5(1):12-14.

吴中伟. (2010). 《当代中文》课本: 印尼语版. 北京: 华语教学出版社.

Departeman Pendidikan dan Kebudayaan. (2002). Kamus Besar Bahasa Indonesia . Jakarta: Balai Pustaka. 